\title{
Article
}

\section{A Critical Analysis of the Hospitalization Network for COVID-19 Patients in Bahia, Brazil in the first wave of the pandemic.}

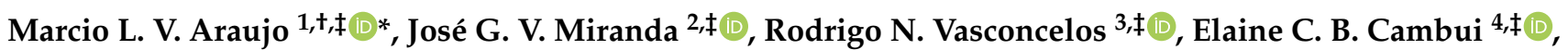

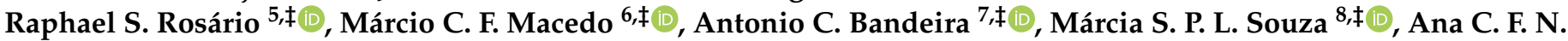

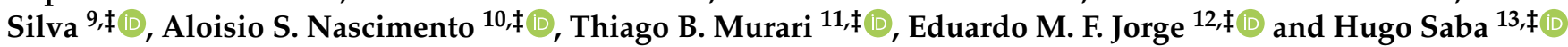

1 Department of Computer Science, Federal Institute of Bahia, Rua São Cristóvão, s/n - Novo Horizonte, Lauro de Freitas - BA, 42700-000; marcioaraujo@ifba.edu.br

2 Department of Physics, Federal University of Bahia, Campus Universitário de Ondina - Ondina, Salvador BA, 40210-340; vivasm@gmail.com

3 Department of Earth and Environmental Sciences, State University of Feira de Santana, Av. Transnordestina, s/n - Feira de Santana, Novo Horizonte - BA, 44036-900; rnvuefsppgm@gmail.com

4 Department of Ecology, Federal University of Bahia, Campus Universitário de Ondina - Ondina, Salvador BA, 40210-340; elainecambui@gmail.com

5 Department of Physics, Federal University of Bahia, Campus Universitário de Ondina - Ondina, Salvador BA, 40210-340; phaoso@gmail.com

6 Department of Computer Science, Federal University of Bahia, Campus Universitário de Ondina - Ondina, Salvador - BA, 40210-340; marciocfmacedo@gmail.com

7 Health Secretary of the State of Bahia, $4^{\text {a }}$ Avenida Centro Administrativo da Bahia, 400 - Centro Administrativo da Bahia, Salvador - BA, 40301-110; antoniobandeira@gmail.com

8 Health Secretary of the State of Bahia, $4^{\mathrm{a}}$ Avenida Centro Administrativo da Bahia, 400 - Centro Administrativo da Bahia, Salvador - BA, 40301-110; marcia.saopedro@saude.ba.gov.br

9 Health Secretary of the State of Bahia, 4 a Avenida Centro Administrativo da Bahia, 400 - Centro Administrativo da Bahia, Salvador - BA, 40301-110; anaclaudianunes@hotmail.com

10 Department of Economy, Senai Cimatec, Av. Orlando Gomes, 1845 - Piatã, Salvador - BA, 41650-010; aloisio.nascimento@gmail.com

11 Department of Economy, Senai Cimatec, Av. Orlando Gomes, 1845 - Piatã, Salvador - BA, 41650-010; mura.learning@gmail.com

12 Department of Exact and Earth Sciences, University of the State of Bahia, R. Silveira Martins, 2555 - Cabula, Salvador - BA, 41180-045; emjorge1974@gmail.com

12 Department of Exact and Earth Sciences, University of the State of Bahia, R. Silveira Martins, 2555 - Cabula, Salvador - BA, 41180-045; hugosaba@gmail.com

* Correspondence: marcioaraujo@ifba.edu.br; Tel.: +5571988896527

+ Current address: Affiliation 1

$\ddagger$ These authors contributed equally to this work.

\begin{abstract}
To effectively combat the COVID-19 pandemic, the state government of Bahia, Brazil, has distributed intensive and non-intensive care units along the nine regions that divide the state of Bahia, such that COVID-19 patients could be easily hospitalized in health care units located at the same regions where they live. However, the observed hospitalizations networks for COVID-19 patients shows that a considerable number of COVID-19 patients had to travel beyond their region of residence to be hospitalized. Hence, this study indicates that the current distribution of health care units in Bahia, Brazil, is not sufficient to effectively reduce the distances traveled by COVID-19 patients requiring hospitalization. We believe that such unnecessary travels to distant hospitals may put the sick patients as well as healthy people involved in the transportation process in risk, further delaying the stabilization of the COVID-19 pandemic in each region of the state of Bahia.
\end{abstract}

Keywords: Government; Hospitalization; Pandemics; Public policy; Transportation. 


\section{Introduction}

The state of Bahia, Brazil, has a total area of approximately 565,000 square kilometers and, by the end of 2020, an estimated population of about 15 million people, which is superior to the estimated population of European countries, such as Belgium, Greece, Sweden, and Portugal [1]. In this sense, while in normal conditions, it is already difficult to provide free, high-quality health care services to the population that live in Bahia, in March 11, 2020, with the World Health Organization (WHO) announcement of the coronavirus disease 2019 (COVID-19) outbreak, caused by the new severe acute respiratory syndrome coronavirus 2 (SARS-CoV-2), as a pandemic, the provision of high-quality health care services has become even more challenging, since the high transmissibility of the SARS-CoV-2 may quickly overload health care services of a state or a country [2].

Possibly inspired by the National Health Service of the United Kingdom [3], the Brazilian National Health System (Sistema Único de Saúde - SUS) is a public health system created by the Constitution of the Federative Republic of Brazil [4]. In the state of Bahia, Brazil, the management of SUS is done by the state government of Bahia, that must provide financial resources and stimulate the municipalities of Bahia to pursue a responsible management of their health care services, and that must also assume that responsibility in the case some of those municipalities are not able to achieve that goal [5].

By the end of October 2020, following the State Contingency Plan for Confrontation of the New Coronavirus SARS-CoV-2 [6], the state government of Bahia distributed 2,286 intensive and non-intensive care units in 61 out of the 417 municipalities of Bahia, in order to provide better assistance to the COVID-19 patients that live in Bahia [7], 41\% higher than the previous healthcare network. Many of these health rooms were created to serve COVID-19 patients, as part of a municipal, state, and federal effort. Therefore, COVID-19 patients that reside in municipalities not capable of providing appropriate treatment or hospitalization for such a disease, must travel to another municipality to be better assisted by SUS. In order to reduce the distance and duration of those travels, the state government of Bahia has distributed health care units into municipalities located into nine regions (i.e., North, Northeast, North-Central, East-Central, East, West, Southwest, South, and Extreme-South) that geographically divide the state of Bahia, such that COVID-19 patients could be ideally treated or hospitalized in health care units available at the regions where they reside, promoting a region-based control of the COVID-19 pandemic inside the state of Bahia.

Related work has already shown that we need to analyze transportation networks between municipalities and states of a country [8][9][10][11] to be able to study the dynamics of dissemination of infectious diseases, such as COVID-19 [12][13][14][15][16][17][18], as well as to evaluate how we can guarantee a safe transportation for COVID-19 patients to be hospitalized in health care units [19][20][21] of Bahia.

In this paper, we aim to evaluate whether the distribution of intensive and nonintensive care units among 61 out of the 417 municipalities in Bahia is enough to assist COVID-19 patients inside each one of the nine distinct regions that divide the state of Bahia. On the basis of a dataset provided by the Health Secretary of the State of Bahia (Secretária de Saúde do Estado da Bahia - SESAB) and by the Brazilian Ministry of Health (Ministério da Saúde do Brasil), from open health systems data, we have built a hospitalizations network for COVID-19 patients in Bahia, Brazil, based on the concepts of complex networks and using geoprocessing. Then, we have analyzed whether COVID-19 patients are indeed being hospitalized in health care units located in the same region where they live, and if that is not the case, what is the relation of importation and exportation of hospitalized COVID-19 patients between distinct regions in Bahia. Another contribution of our work is the presentation of the DESH (Degree of External Search for Hospitalization) index, which estimates the saturation level of the municipalities that offer in-hospital assistance for COVID-19 patients that come from other regions of the state of Bahia. We believe that the discussions presented in this paper may be helpful to the state government of Bahia, which may improve its decision-making process to effectively control the COVID-19 pandemic in 
Bahia, and we also believe that this kind of study may be replicated for other states and countries around the world, to verify whether the hospitalizations networks previously estimated by governments match the real ones obtained in practice.

\section{Materials and Methods}

\subsection{Data Collection}

In this study, we considered the COVID-19 patients that were hospitalized in intensive or non-intensive care units provided by SUS in the state of Bahia, Brazil between March 1, 2020 and July 30, 2020, and that have been reported in the hospital systems. To build the hospitalizations networks, we included 4,387 COVID-19 patients that were hospitalized in municipalities distinct to the ones where they were residents at the time of the diagnosis, with the goal of identifying whether those patients had to travel large distances to be hospitalized due to the unavailability of health care units in their municipality of residence.

\subsection{Hospitalization Network}

On the basis of the graph theory, we represent the hospitalizations networks for COVID-19 patients in Bahia as a directed graph, where each node is assigned to a municipality in Bahia, each node's size is directly proportional to its DESH index to be presented in the next subsection, each directed edge represents a travel going from an origin (i.e., municipality of residence) to a destination (i.e., municipality of hospitalization), and each directed edge is weighted by the number of patients that traveled between the corresponding pair of origin-destination municipalities. Hence, the hospitalizations networks provides a visual representation of the patients that needed to be hospitalized because of the severity of COVID-19, but could not be hospitalized in their municipality of residence due to the unavailability of a health care unit at that location and at that moment.

\subsection{Simulation of the Expected Network}

In order to evaluate whether the strategy of the state government of Bahia to distribute health care units among the nine regions in Bahia has been successful, we simulated the expected hospitalizations networks idealized by the state government. To do so, we redirected each edge of the observed hospitalizations networks to connect the node representing the municipality of residence of the patient to another node representing the closest municipality with an available health care unit, such that each redirected edge could represent the expected path traveled by a patient when searching for hospitalization by COVID-19 in Bahia.

\subsection{DESH (Degree of External Search for Hospitalization) Index}

To favor a comparison between the level of assistance and hospitalization provided by each region of the state of Bahia, we have developed the DESH index. With such an index, we can measure the saturation level of the 61 municipalities able to hospitalize COVID-19 patients. While each one of those 61 municipalities must provide assistance to the internal demand for hospitalization, by providing support to the patients that live inside the corresponding municipality, the DESH index only takes into account the external demand for hospitalization. In other words, this index measures how much each municipality is involved in the importation of COVID-19 patients provided by other municipalities that could be located inside or outside of the corresponding region of the state of Bahia.

The DESH index of a municipality $i$, or node $i$, with at least one intensive or nonintensive care unit available, can be described in terms of the following Equation 1:

This is the example 2 of equation:

$$
D_{E S H}=\frac{\sum_{j=1}^{N-1} w_{i j}}{\gamma_{i}}
$$

, where wij is the weight of a directed edge that connects the node $i$ to the node $j$ (i.e., number of patients that traveled from municipality $j$ to municipality $i), i$ is the total number 
of intensive and non-intensive care units available at that municipality $\mathrm{i}$, and $\mathrm{N}$ is the total number of municipalities being evaluated.

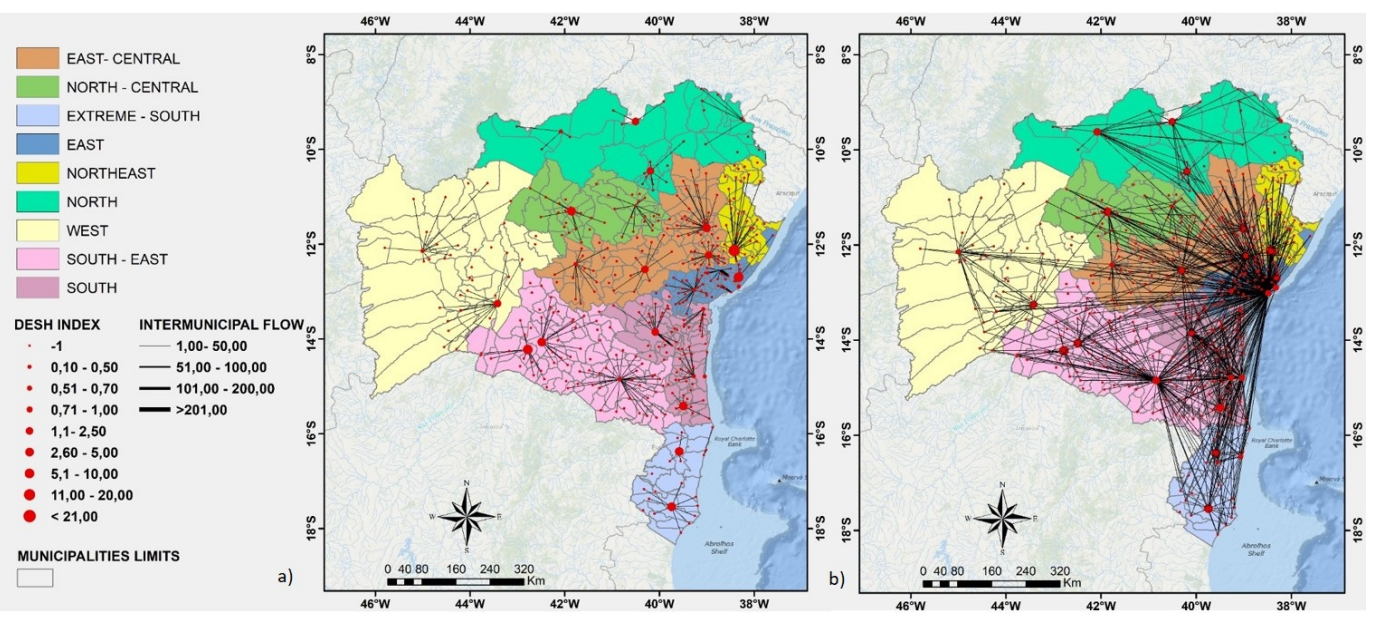

Figure 1. A visual comparison between the expected (a) and observed (b) hospitalizations networks for COVID-19 patients in Bahia, Brazil. Source: Author.

Each one of the nine regions of Bahia is represented by a specific color. Each node (red circle) of the directed graph represents a municipality of Bahia. Each node size is directly proportional to its DESH index. The weight of each directed edge (black line) is directly proportional to the number of patients that have been transported to the corresponding municipality for hospitalization.

\section{Results}

As we can see in Figure 1a, according to the original planning of the state government of Bahia, even if not every one of the 417 municipalities of Bahia has a reference hospital or health care unit able to treat COVID-19 patients, the expected hospitalizations networks for COVID-19 patients would be the one in which each patient would be hospitalized in the nearest reference unit available in the region where the patient is residing, such that COVID-19 patients would travel a distance as minimum as possible to be hospitalized, consequently allowing for a faster and more efficient treatment of those patients, as well as for a lower exposition to the COVID-19 of the professionals involved in the transportation process. Hence, as can be seen by the weights of the directed edges shown in Figure 1a, once the health care units of each region would concentrate the hospitalization cases of the patients that live in the corresponding municipalities, the hospitalizations networks would be more distributed all over the state, and the COVID-19 pandemic could be handled locally, per region of the state of Bahia. However, on the basis of the anonymized data collected from SESAB, we could estimate that the observed hospitalizations networks for hospitalized patients are more similar to the one illustrated in Figure 1b. In this case, we can see that several COVID-19 patients need to travel from one region to another to be properly hospitalized, which suggests that some regions of the state of Bahia are not able to handle the high demands of hospitalization that may be happening due to COVID-19. In an ideal, expected scenario depicted in Figure 1a, each region would hospitalize only resident patients diagnosed with COVID-19. However, Table 1 shows that, while both North, East, and Southwest regions exported a few patients to the other regions of the state of Bahia, North-Central, East-Central, and Northwest regions exported more than three times the number of patients that they could hospitalize. We can also observe that both East and Southwest regions concentrate the highest percentage of imported hospitalizations. In this case, it is worthy to note that almost $50 \%$ of the hospitalizations done in the East region, that includes the capital of the state of Bahia, Salvador, are imported from other regions, while only $0.5 \%$ of the hospitalized cases are exported to other regions. 
Table 1. A numerical overview of the observed hospitalizations networks for COVID-19 patients with respect to the nine regions of the state of Bahia.

\begin{tabular}{cccc}
\hline Region & $\begin{array}{c}\text { Patients that live in } \\
\text { that region }\end{array}$ & $\begin{array}{c}\text { Patients imported } \\
\text { from other regions }\end{array}$ & $\begin{array}{c}\text { Patients exported to } \\
\text { other regions }\end{array}$ \\
\hline North & $158(81.9 \%)$ & $0(0.0 \%)$ & $35(18.1 \%)$ \\
Northeast & $11(3.7 \%)$ & $0(0.0 \%)$ & $290(96.3 \%)$ \\
North-Central & $12(12.9 \%)$ & $2(2.2 \%)$ & $79(84.9 \%)$ \\
East-Central & $77(10.7 \%)$ & $70(9.7 \%)$ & $571(79.5 \%)$ \\
East & $1,686(54.9 \%)$ & $1,369(44.6 \%)$ & $14(0.5 \%)$ \\
West & $62(67.4 \%)$ & $0(0.0 \%)$ & $30(32.6 \%)$ \\
Southwest & $263(54.3 \%)$ & $140(28.9 \%)$ & $81(16.7 \%)$ \\
South & $401(47.3 \%)$ & $61(7.2 \%)$ & $385(45.5 \%)$ \\
Extreme-South & $74(31.8 \%)$ & $1(0.4 \%)$ & $158(67.8 \%)$ \\
\hline
\end{tabular}

\section{Discussion}

One of the main problems caused by such an unbalanced observed hospitalizations networks is illustrated in Figure 2, which shows that, while in the expected hospitalizations networks, some travels would be required to transport patients between the municipalities of the same region, in the observed scenario, more patients needed to travel longer distances to be hospitalized outside of their region of residence.

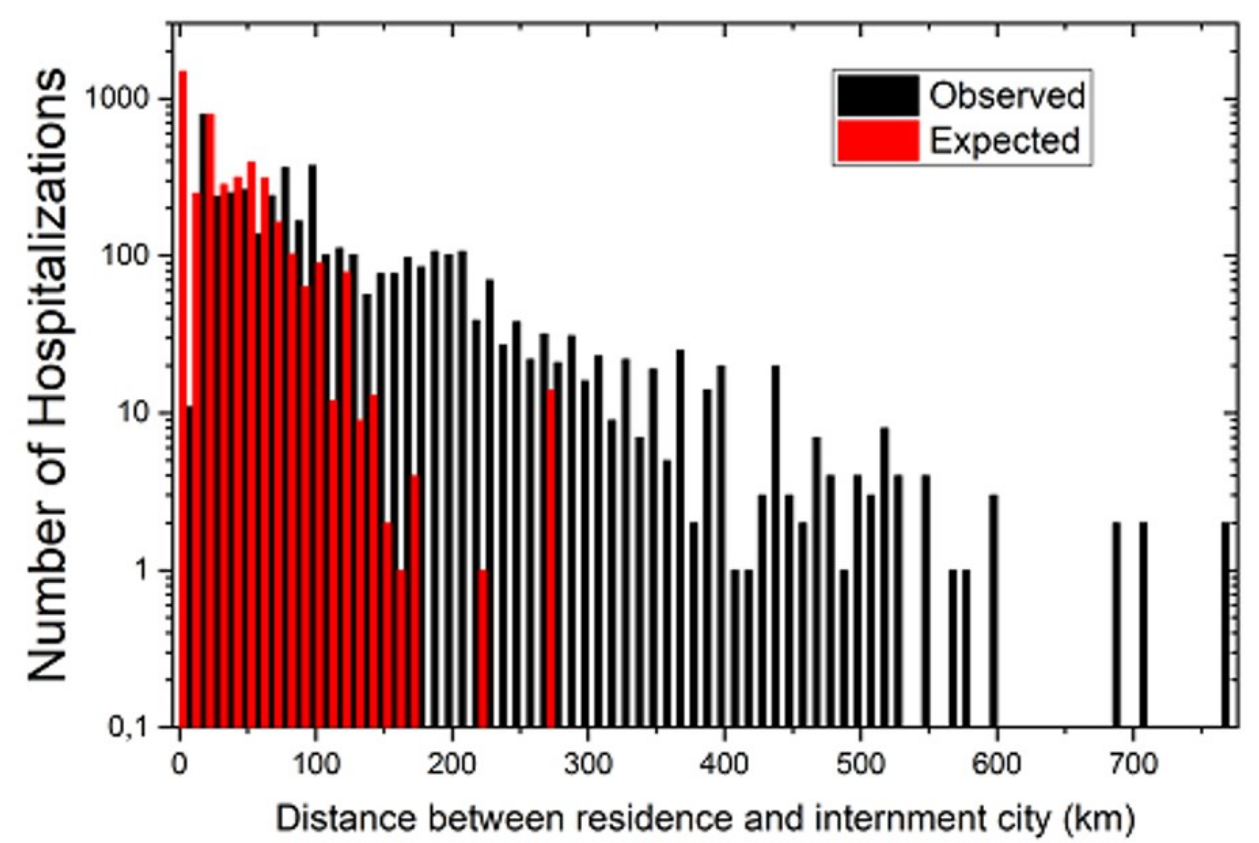

Figure 2. A histogram with the frequencies of expected (red) and observed (black) distances traveled by COVID-19 patients. Source: Author.

In our point of view, that unnecessary transportation of patients may affect the state of Bahia in two ways: First, this scenario may reduce the effectiveness in the reduction of the number of new cases of COVID-19 per region of the state of Bahia, since new patients diagnosed with COVID-19 might end up being hospitalized in another region that has already stabilized the COVID-19 pandemic, exposing healthcare professionals of such a region to the coronavirus, that, once infected by COVID-19, could further disseminate such an infectious disease to other people, contributing to a new rise in the number of new cases of COVID-19 per day. Second, that unnecessary transportation may result in additional costs for the state and the municipalities of Bahia, since they both are financially responsible for the management of the healthcare professionals and the infrastructure required to realize the transportation of the patients to be hospitalized, and also for the 
maintenance of the intensive and non-intensive care units that otherwise would be empty or at least less occupied, assuming a scenario in which a region is exporting new COVID-19 patients to be hospitalized in another region that has achieved stabilization with a few new cases of COVID-19.

In Figures 3, 4, 5 e 6, we show a more detailed visualization of the observed hospitalizations networks previously shown in Figure $1 \mathrm{~b}$. These figures detail the transportation network for hospitalized COVID-19 patients with a focus on the relation between distinct regions of the state of Bahia and the East region, which has the capital of the state of Bahia, the highest number of intensive and non-intensive care units, and concentrates the highest number of imported patients from other regions.

A high number of patients of the regions that are neighbours of the East region, such as the East-Central (Figure 3a), Northeast (Figure 5e), and South (Figure 6h), are hospitalized in the East region, which may indicate that there is an unbalanced distribution of health care units in those neighbour regions. Moreover, Figures 3, 4, 5 e 6 shows that the regions that are more distant to the East one, such as the North-Central (Figure 3b) and Extreme-South (Figure 4c), also contribute to the exportation of patients to the East region. On the other hand, both West (Figure 6g) and North (Figure 5f) regions are able to handle the demand for the hospitalization of their patients, even through the West region exported some patients for hospitalization in the East and Southwest regions, and the North region also exported some cases for hospitalization in the East region.
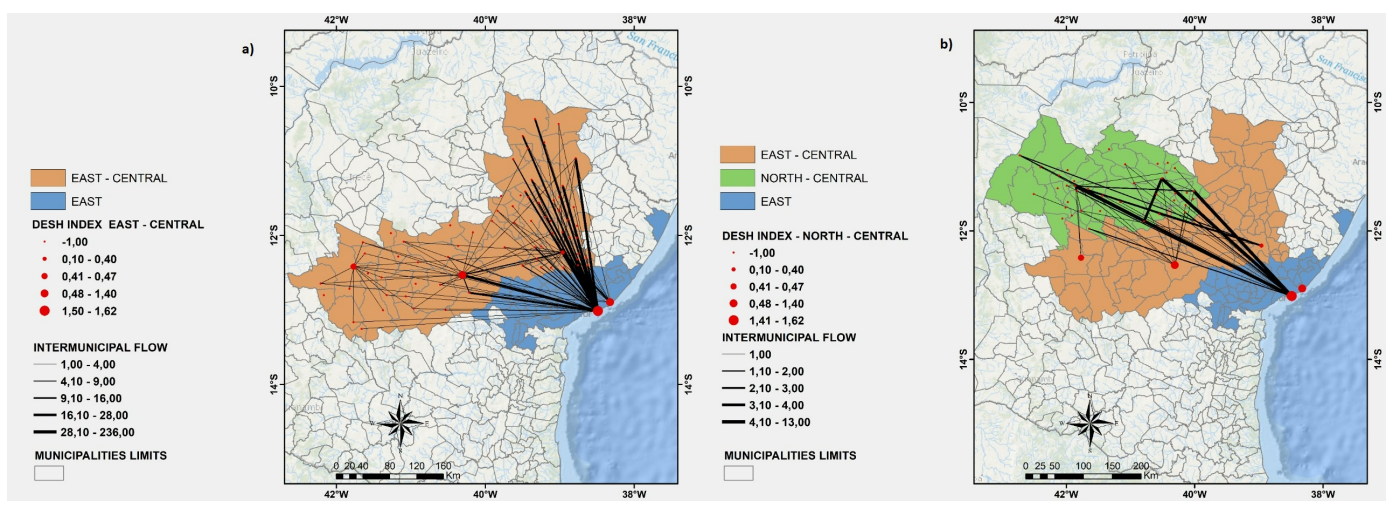

Figure 3. A visualization for the regions: East, East-Central and North-Central. Source: Author.
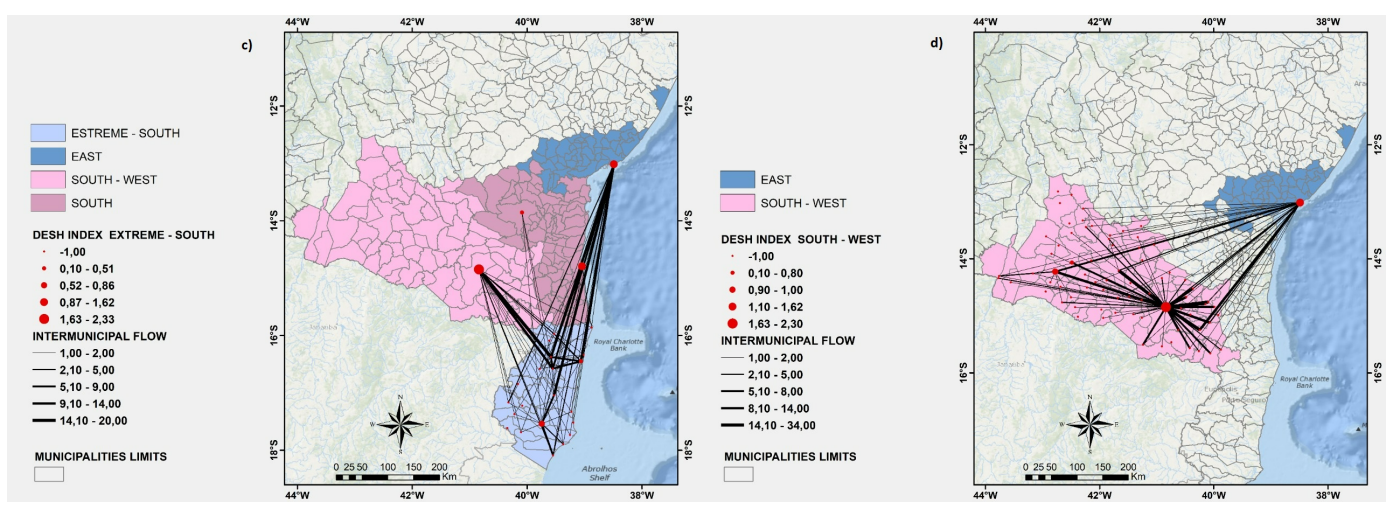

Figure 4. A visualization for the regions: Extreme-South, East, South-West and South. Source: Author. 

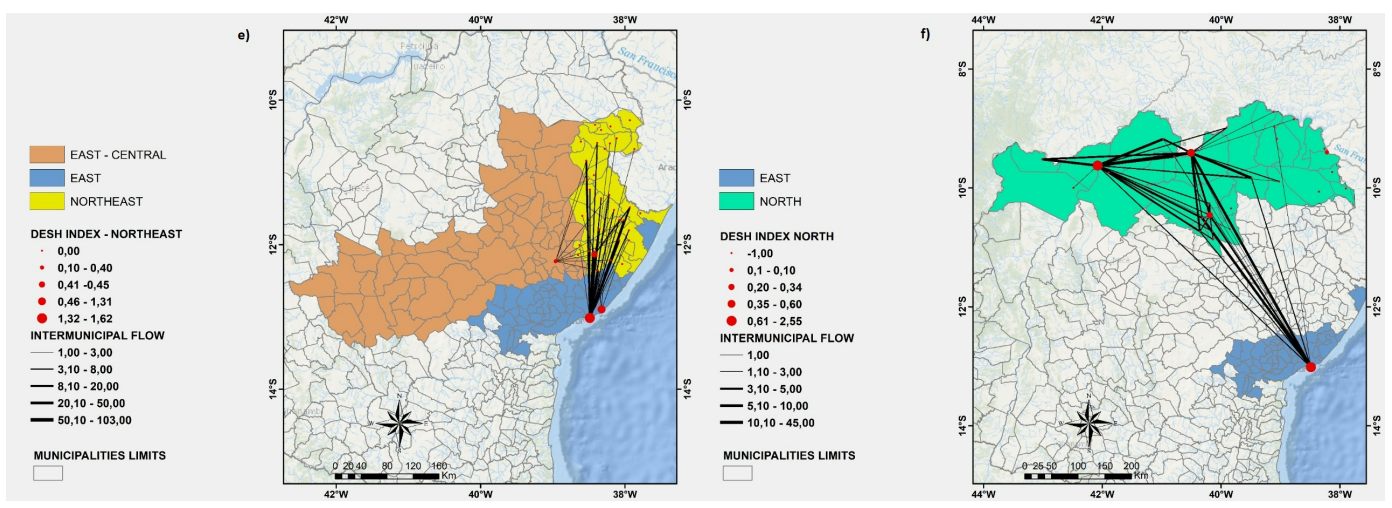

Figure 5. A visualization for the regions: East-Central, East, Northeast and North. Source: Author.
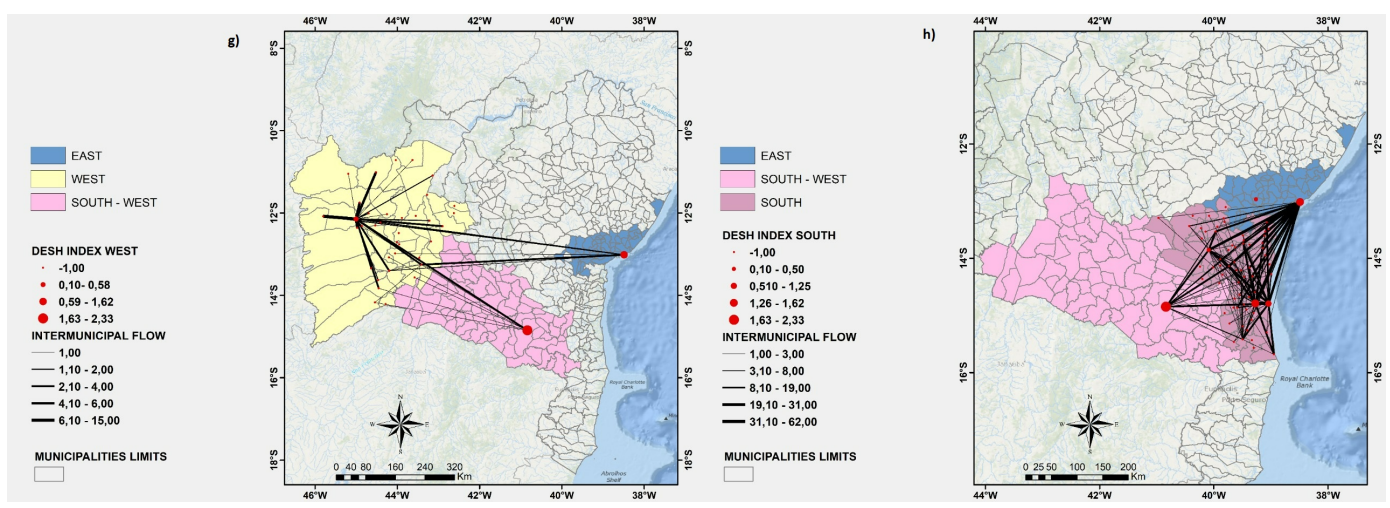

Figure 6. A visualization for the regions: East, West, South-West and South.. Source: Author.

\section{Conclusions}

COVID-19 is a dangerous infectious disease that requires new policies of the governments in order to effectively combat the further prolongation of this pandemic. In this sense, the provision and distribution of new hospitals and health care units able to assist and hospitalize COVID-19 patients is desirable to allow for a faster and more effective treatment of those patients.

As we have shown in this paper, the distribution of intensive and non-intensive care units in the state of Bahia, Brazil, has some limitations, since many patients had to travel more than 300 kilometers to be hospitalized, as shown in Figure 2. Hence, a redistribution of the available health care units, or alternatively a selective, adaptive expansion of the health care infrastructure in the regions that are exporting most of their patients to be hospitalized in another region, may contribute to a more successful reduction in the length of these travels.

It is known that the state of Bahia has a health care regulation system, and it can be seen from the results of this research that the logistics included in the process of control and distribution of care, needs to be reviewed. Not only based on the number of inhabitants per square meter in a health region or city, but also by the need for certain medical specialties or the growth in demand for care.

Finally, we hope that the publication of this manuscript could be an encouraging factor for the state government of Bahia, and other governments around the world, to reproduce the methodology presented in this paper, in order to better evaluate the we show a more detailed visualization of the observed hospitalizations networks previously for hospitalized patients of COVID-19 and for other diseases, and see whether the expected strategies previously planned are being observed in practice and thus reducing the social impact and mortality. 
Author Contributions: Conceptualization: Authors 1, 2, 3, 4, 8 and 13; Methodology: All authors; Software: Authors 1, 2, 3, 4, 5, 12 and 13; Validation: All authors; formal analysis: All authors; Investigation: All authors; Resources: Authors 1, 7, 8, 9, 10, 1112 and 13; Data curation: Authors 1, 2, 8, 9 and 13; Writing—original draft preparation: All authors; Writing—review and editing: All authors; Visualization: All authors; Supervision: Authors 1 and 13; Project administration: Authors 1 and 13; Funding acquisition: Authors 1, 8, 9 and 13. All authors have read and agreed to the published version of the manuscript.

Funding: This research was funded by PPSUS 02/2020 PROJECT, grant number: 4370/2020. Hugo Saba received financial support from the National Council for Scientific and Technological Development - CNPq (http:/ / cnpq.br/), grant numbers 431990 / 2018-2 and 13423 / 2019-9

Institutional Review Board Statement: Not applicable. The data used in this research were anonymous, without any personal data of the patients.

\section{Informed Consent Statement: Not applicable}

Data Availability Statement: The original database used is public and available at: https://bi. saude.ba.gov.br/transparencia/, https:/ / opendatasus.saude.gov.br/dataset/srag-2020 and https: // opendatasus.saude.gov.br/dataset/srag-2021-e-2022. Summarized data from hospitalizations used in the analysis https://github.com/dataNPAI/UTIdata.git

Acknowledgments: This work was supported by: The Foundation for Research Support of the State of Bahia - FAPESB and the National Council for Scientific and Technological Development - CNPq.

Conflicts of Interest: The authors declare no conflict of interest. The funders had no role in the design of the study; in the collection, analyses, or interpretation of data; in the writing of the manuscript, or in the decision to publish the results.

$\begin{aligned} & \text { Abbreviations } \\ & \text { The following abbreviations are used in this manuscript: }\end{aligned}$
$\begin{array}{ll}\text { CNPQ } & \text { National Council for Scientific and Technological Development } \\ \text { COVID-19 } & \text { Coronavirus Disease } 2019 \\ \text { DESH } & \text { Degree of External Search for Hospitalization } \\ \text { FAPESB } & \text { The Foundation for Research Support of the State of Bahia } \\ \text { SESAB } & \text { Health Secretary of the State of Bahia } \\ \text { SUS } & \text { Brazilian National Health System } \\ \text { WHO } & \text { World Health Organization }\end{array}$

\section{References}

1. Brazilian Institute of Geography and Statistics. Estimated population in Bahia, Brazil. Available online: https://cidades.ibge.gov.br/brasil/ba/panorama (accessed on 20 november 2021).

2. World Health Organization. Considerations for quarantine of individuals in the context of containment for coronavirus disease (COVID-19): interim guidance. No. WHO/2019-nCov/IHR_Quarantine/2020.1.

3. Tanaka OY, Oliveira VE. Reforms and organization of the British National Health System: lessons to the Brazilian National Health System. Saúde e sociedade 2007, 16, 7-17. https:/ / doi.org/10.1590/S0104-12902007000100002.

4. Constitution of the Federative Republic of Brazil Available online: http://www.planalto.gov.br/ccivil_03/constituicao/constituicao.htm (accessed on 20 november 2021).

5. Lei Orgânica de Saúde. Lei no 8.080. 1990. Available online: http://www.planalto.gov.br/ccivil_03/leis/18080.htm (accessed on 20 november 2021).

6. Health Secretary of the State of Bahia. Plano Estadual de Contingências para Enfrentamento do Novo Coronavírus - SARS - CoV 2. Available online: http://http:/ / www.saude.ba.gov.br/wp-content/uploads/2020/06/Plano-de-Continge\%CC\%82ncia-Coronav\%C3\%ADrusBahia-2020-2606.pdf (accessed on 20 november 2021).

7. Health Secretary of the State of Bahia. Central Integrada de Comando e Controle de Saúde - COVID-19. Available online: https:/ / bi.saude.ba.gov.br/transparencia/ (accessed on 20 january 2022).

8. Saba H, Vale VC, Moret MA, Miranda, JCV. Spatio-temporal correlation networks of dengue in the state of Bahia. BMC Public Health 2014, 14, 1085. https:/ / doi.org/10.1186\%2F1471-2458-14-1085 
9. Saba H, Moret MA, Barreto FR, Araujo MLV, Jorge EMF, Filho ASN, et al. Relevance of transportation to correlations among criticality, physical means of propagation, and distribution of dengue fever cases in the state of Bahia. Sci. Total Environ 2018, 618, 971-976. https://doi.org/10.1016/j.scitotenv.2017.09.047

10. Tiracini A, Cats O. COVID-19 and public transportation: Current assessment, prospects, and research needs. J Public Trans 2020, 22, 1. https:/ / doi.org/10.5038/2375-0901.22.1.1

11. Zheng R, Xu Y, Wang W, Ning G, Bi Y. Spatial transmission of COVID-19 via public and private transportation in China. Travel Med Infect Dis 2020, 34, 101626. https://doi.org/10.1016\%2Fj.tmaid.2020.101626

12. Du Z, Wang L, Cauchemez S, Xu X, Wang X, Cowling BJ, et al. Risk for Transportation of Coronavirus Disease from Wuhan to Other Cities in China. Emerg. Infect. Dis [Internet] https://wwwnc.cdc.gov/eid/article/26/5/20-0146_article. (accessed on 20 november 2021).

13. Wei JT, Liu YX, Zhu YC, Qian J, Ye RZ, Li CY, et al. Impacts of transportation and meteorological factors on the transmission of COVID-19. Int. J. Hyg. Environ. Health 2020, 230, 113610. https://doi.org/10.1016/j.ijheh.2020.113610

14. Lee H, Park SJ, Lee GR, Kim JE, Lee JH, Jung Y, et al. The relationship between trends in COVID-19 prevalence and traffic levels in South Korea. Int. J. Infect. Dis. 2020, 96, 399-407. https://doi.org/10.1016/j.ijid.2020.05.031

15. Carmo RF, Nunes BEBR, Machado MF, Armstrong AC, Souza CDF. Expansion of COVID-19 within Brazil: the importance of highways. J. Travel Med 2020, 27. https://doi.org/10.1093/jtm/taaa106

16. Zhong P, Guo S, Chen T. Correlation between travellers departing from Wuhan before the Spring Festival and subsequent spread of COVID-19 to all provinces in China. J. Travel Med 2020, 27. https://doi.org/10.1093/jtm/taaa036

17. Hu M, Lin H, Wang J, Xu C, Tatem AJ, Meng B, et al. The risk of COVID-19 transmission in train passengers: an epidemiological and modelling study. Clin. Infect. Dis. 2020. https://doi.org/10.1093/cid/ciaa1057

18. Bajardi P, Poletto C, Ramasco JJ, Tizzoni M, Colizza V, Vespignani A. Human Mobility Networks, Travel Restrictions, and the Global Spread of 2009 H1N1 Pandemic. PLoS ONE 2011, 6. 16591. https:/ /doi.org/10.1371/journal.pone.0016591

19. Liew MF, Siow WT, Yau YW, See KC. Safe patient transport for COVID-19. Crit Care 2020, 24.1-13. https://doi.org/10.1186\%2Fs13054-020-2828-4

20. Brown AS, Hustey FM, Reddy AJ. Interhospital transport of patients with COVID-19: Cleveland Clinic approach. Cleve Clin J Med 2020. https://doi.org/10.3949/ccjm.87a.ccc045

21. Macedo, Márcio CF et al. Correlation between hospitalized patients' demographics, symptoms, comorbidities, and COVID-19 pandemic in Bahia, Brazil. PloS one 2020, v. 15, n. 12. e0243966. https://doi.org/10.1371/journal.pone.0243966 